\title{
Una familia de meretrices: prostitutas públicas y privadas, cortesanas, rameras y putas viejas en La Celestina ${ }^{1}$
}

\author{
Jorge Abril-Sánchez \\ University of Massachusetts-Amherst
}

Como dice Aristóteles, cosa es verdadera, El mundo por dos cosas trabaja: la primera, Por aver mantenençia; la otra cosa era Por aver juntamiento con fenbra placentera.

(Juan Ruiz, Libro de buen amor)

EL ORIGEN DE la prostitución en España se remonta a civilizaciones anteriores a la adopción de la religión católica y sus valores ético-morales. Ya en la cultura fenicia que prosperó antes de la era romana había una gran libertad sexual que se vio interrumpida por la llegada de los visigodos, que prohibieron todo tipo de actividad prostibularia - tanto heterosexual como homosexual- asignándole penas como la castración y el exilio. Fue una época de control de las pasiones que se acabó con el asentamiento de pueblos islámicos en el sur de la península a principios del siglo viII. La cultura de Al-Andalus tenía muchas similitudes con la helenística, y se caracterizaba por su hedonismo y su permisividad. La prostitución era una práctica extendida por todo el territorio taifa y dejó una profunda huella en la sociedad hispana durante los siete siglos de gobierno musulmán. Con la Reconquista, las costumbres cristianas se enfrentaban con las heredadas de períodos anteriores. La Celestina es un reflejo de la confrontación entre los nuevos códigos legislativos y la práctica de la prostitución en la sociedad española de finales del siglo XV.

El objetivo de este estudio es reflejar el contexto social de la España medieval y la condición legal de las prostitutas en una sociedad cristianizada. Mi intención es crear el esquema de un grupo familiar, estableciendo una clasificación de los diferentes tipos de mujer pública que existían, sus características y su identificación con cinco de los personajes femeni-

1. Para las citas textuales de La Celestina utilizo la edición de Dorothy S. Severin publicada en Cátedra. 
nos de la obra celestinesca, a saber, Celestina, Elicia, Areúsa, Lucrecia y, paradójicamente también, Melibea. Mientras que la alcahueta y las dos rameras han sido objeto de numerosos estudios ${ }^{2}$, tanto a Lucrecia como, sobre todo, a Melibea no se las ha analizado bajo las mismas condiciones por miedo a traspasar fronteras de clase que intentaré desmitificar ${ }^{3}$. Alan Deyermond ve muchos paralelismos entre la joven doncella y las mujeres públicas, pero se niega a tratar a Melibea como tal por ser de clase alta (12), lo cual no tiene base histórica pues hubo muchas mujeres nobles que se vieron atraídas por la profesión debido a la presencia de alcahuetas y de prostitutas en las plazas públicas. María Eugenia Lacarra comenta que había diferentes tipos de prostitución:

Entre las que se dedican a la prostitución, nos encontramos con tres tipos: las 'putas que están públicamente en la putería', las mujeres malas, pero no conocidas como putas, $y$ las mujeres forzadas a prostituirse por su relación de dependencia con los alcahuetes. Un grupo aparte lo forman las que gozan de buena fama, mujeres, hijas o viudas de vecinos y religiosas, a quienes los alcahuetes no necesariamente prostituyen sino que seducen de manera puntual. (37; énfasis mío)

Según este esquema, Melibea sería una joven noble que ejerce la prostitución de forma esporádica, por su relación con Celestina y por lo que ve hacer a sus vecinas. Así, la vestimenta y la conducta, y no su linaje, crearán las categorías ${ }^{4}$ de puta vieja, prostituta pública, cortesana, puta joven y prostituta privada a las que estas mujeres pertenecen, respectivamente.

En la España del siglo xv, la actividad prostibularia había echado profundas raíces en la sociedad. Careciendo apenas de códigos legales que la condenaran, se había convertido en una práctica social muy popular entre jóvenes mozos, enamoradizos y pecadores que acudían a los servicios de estas mujeres públicas para satisfacer sus pasiones. El prostíbulo, al igual que el convento, la casa de la viuda y la corte, representaba una de las «micro-sociedades» ${ }^{5}$ que existían dentro de la ciudad del Medioevo pues en ella se juntaban las rameras con sus pretendientes. Había una

2. Sólo como apunte podría mencionar los desarrollados por Barbera y Foster.

3. Últimamente, proyectos cinematográficos como el de Vera (1995) han intentado tratar este asunto mediante un «casting" premeditado de actrices y el diseño de sus vestidos. La postura no es muy clara y mantienen la incógnita para no romper moldes aunque ya adelantan interpretaciones personales. Mi intención es deconstruir ese modelo de doncella noble que parece ser intocable.

4. Para la elección de estas categorías, me he basado en aspectos pertenecientes al personaje o al nombre que se usa para referirse a ellas.

5. Para un estudio más profundo del tema de la micro-sociedad femenina, aconsejaría leer el maravilloso artículo de Alan Deyermond. 
gran proliferación de burdeles tanto en la zona musulmana como en la cristiana. De hecho, en Salamanca, ciudad donde se ha intentado buscar la verdadera casa de Celestina, se abrió una mancebía en la última década del siglo xv en la misma época en la que Fernando de Rojas escribió allí su obra, por lo que la tragicomedia podría constituir un verdadero documento histórico-social de la prostitución en la España medieval ${ }^{6}$.

Las rameras tenían el favor de la sociedad y eran protegidas por los caballeros que las adoraban. Así, Celestina le cuenta a Sempronio que la madre de Pármeno «jamás volvía sin ocho o diez gustaduras un açumbre en el jarro y otro en el cuerpo. Assí la fiavan dos o tres arrobas en vezes, como sobre una taça de plata. Su palabra era prenda de oro en quantos bodegones avía. Si ývamos por la calle dondequiera que ovíssimos sed, entrávamos en la primera taverna» (III: 143). Raymond Barbera apunta que las prostitutas y las alcahuetas hacían un servicio a la comunidad pues rompían con los tapujos moralistas de una sociedad donde se pretendía mantener el honor y la honra intacta (796). Sólo cuando se extendieron las enfermedades venéreas en el siglo XVII se produjo el cierre de los prostíbulos porque hasta entonces los burdeles tenían buena fama y los municipios los protegían ya que se beneficiaban de los impuestos que regulaban su actividad.

Las tabernas ${ }^{7}$ eran otro de los lugares que las rameras solían frecuentar y donde llevaban a cabo sus negocios. Hay numerosas alusiones en $\mathrm{La}$ Celestina a la relación de las prostitutas con el vino ${ }^{8}$, y de cómo los hombres se perdían al buscar los placeres de la mesa y la cama. Sempronio avisa a su amo de que «las mujeres y el vino hazen a los hombres renegar» (I: 96-97), y cuando ve a Sempronio venir con Celestina Pármeno llama a la alcahueta «puta vieja alcoholada» (I: 108). Por otra parte, cuando Tristán ve a Sosia venir a casa, tras la muerte de los sirvientes, le dice a Calisto que «desgreñado viene el vellaco; en alguna taverna se deve aver rebolcado» (XIII: 277). Los criados eran los que más frecuentaban estas po-

6. Lacarra comenta que era tal la afinidad de los ciudadanos con sus «vecinas» que cuando en 1497 el príncipe don Juan otorgó el derecho de establecer una casa pública a un soldado del Ejército Real, todo el municipio se quejó a la reina Isabel para que la sorteara al mejor postor (40-41).

7. Lacarra comenta que "Claro que la prostitución no solo se practicaría en casas particulares, pues las ventas y mesones eran tradicionalmente lugares de gran actividad prostibularia, como se deduce de las ordenanzas salmantinas que obligaban a venteros y mesoneros a anunciar su negocio con una tabla y les prohibía acoger 'muger que gane con su persona ni pública ni secretamente, ni biua escandalosamente'» (42-43; énfasis mío).

8. Esto ya viene de la tradición clásica con las Bacanales, fiestas en honor al dios griego Baco, y se mantiene a lo largo de la historia hasta nuestros tiempos. En el siglo xviII, en su Iconología, Cesare Ripa representa al hombre sanguíneo divirtiéndose en fiestas por ser de alegre naturaleza. De los elementos que caracterizan su descripción destacan los racimos de uva colocados junto a él y un carnero, ambos símbolos del placer sexual. Además, se creía que el vino era un producto afrodisíaco que despertaba el apetito sexual (Emblema CVI). 
sadas porque su condición social no les permitía aspirar a una cortesana o a una prostituta privada.

Era, sin duda, una sociedad promiscua. Por una parte, Calisto va frecuentemente a la iglesia de la Magdalena, lo que sugiere un culto a la santa que se había dedicado a la prostitución. Se venera a la mujer pública pero a diferencia de la Magdalena no parece que haya propósito de enmienda. Por otra parte, en La Celestina, la vieja alcahueta tiene mucho trabajo no sólo arreglando los amores de "cavalleros, viejos [y] moços, abades de todas dignidades, desde obispos hasta sacristanes» (IX: 235), sino también cosiéndoles el himen a las mozas que habían perdido la virginidad, lo cual demuestra que las damas nobles se estaban viendo atraídas por la pasión sexual ${ }^{9}$. David Wise señala que se condenaba socialmente a las mujeres por los malignos efectos que el amor producía sobre el hombre, y por las despreciables características de las mujeres, ya que nunca respondían al amor de un hombre por estar interesadas sólo en el dinero y los beneficios que obtenían (506-07). Las mujeres públicas controlan los deseos de los hombres en todo momento y los manipulan concediéndoles el fruto preciado cuando ellas saben que nadie les va a impedir que consigan algo a cambio. Se podría leer así el primer encuentro de Calisto y Melibea. En su cita en el huerto, cuando se espera que los dos amantes puedan encontrarse a solas por primera vez, Melibea convence a Calisto a posponer la ocasión para el día siguiente, para cuando ella ya hubiera preparado todo y no pudiera ser descubierta (XII: 262). Por el contrario, el amante, en general, sea Calisto sea cualquier criado, presentaba rasgos del hombre sanguíneo pues era «muy alegre, franco e riente e placentero [...] mucho enamorado e su coraçón arde como fuego, e ama a diestro e a siniestro» (Martínez 212). Se regía por el lema latino carpe diem, amor vincit omnia. Por ello, Celestina constantemente recuerda a sus protegidos la brevedad de la vida y la necesidad de disfrutar de los placeres que nos ofrece. Además, sus relaciones se ajustaban al modelo de amor ovidiano, es decir, se buscaba el amor pero no se sufría por él porque se basaba en una atracción sexual y sólo se perseguía la satisfacción. Así, Sempronio y Pármeno acuden a sus queridas cuando les interesa. David W. Foster comenta que este amor es más característico de las clases bajas, mientras que las clases altas ansiaban conseguir el amor cortés (486-87). No obstante, en este caso, el amor noble se ve determinado por la consumación del deseo, producto de la lujuria, lo cual lo convierte en un amor más mundano que espiritual. Melibea y Calisto satisfacen sus necesidades durante el mes de su relación de la misma forma que los criados lo hacían en

9. En la Demanda del Corbacho, Martínez de Toledo pide perdón por haber podido ofender a alguna doncella de la corte con su crítica al comportamiento lujurioso de las mujeres por lo que se puede entender que había damas nobles cuyo ideal hedonista de la vida se asemejaba al de las prostitutas públicas (304-6). 
los burdeles, lo cual me llevará a considerar a Calisto otro de los «putillos» (IX: 232) que acuden a pedir ayuda a Celestina. Melibea, en cambio, se quedaría dentro de la categoría de prostituta, en este caso privada, por recibir a su querido en su casa. De hecho, al igual que las otras rameras, ella persigue el amor hedonista por ser el centro de su vida, aunque mantiene ciertas diferencias con el resto de compañeras de profesión pues cuando éste desaparece con la muerte de su amado, en vez de buscar otro amor, se suicida ya que en realidad se enamora de su amante al mismo tiempo que satisface su pasión sexual.

En la obra, Celestina justifica a Pármeno esta conducta placentera con la excusa de «que es forçoso el hombre amar a la mujer y la mujer al hombre» (I: 118), ya que era más una necesidad natural que un vicio pues si no se tenían relaciones "la tuya [punta de la barriga] hincha por nueve meses» (I: 118). Esta libertad sexual sólo se veía limitada por ataques raciales. Finalizada la Reconquista se quería controlar el índice de judíos conversos y moriscos en la península y no se dejaba que éstos acudieran a los burdeles. Calisto, cuya herencia racial había sido "ensuciada» por el desliz de su abuela ${ }^{10}$, no reunía las condiciones para entrar en una de estas casas públicas. Prefiere, sin embargo, aspirar al amor de Melibea, una "noble doncella»; no obstante, al transmitir su linaje de discutida pureza a un miembro de la clase alta está atentando aún más contra la estabilidad de la sociedad ${ }^{11}$, que empezó a ver en la prostitución de las mozas un peligro para el honor y la honra de las jóvenes doncellas. Una prueba de esta preocupación es el hecho de que se aprobara una ley en contra de las alcahuetas que atraían a las hijas de familias nobles al mundo de la prostitución. En el Libro Iv Título x Ley vir del Fuero Real, se dice que "toda mugier que por alcauetería fuere en mandado dalgún omne a mugier casada o desposada, si pudier ser sabudo por prueua o por sennales manifiestas, el alcahueta e el que la enuía sean presos e metidos en poder del marido o del esposo por fazer dellos lo que quisiere sin muerte e sin lisión de sus cuerpos» (443).

10. En el comentario de Sempronio «Lo de tu abuela con el ximio, ¿hablilla fue? Testigo es el cuchillo de tu abuelo» (I: 96), la crítica ha querido ver un pasado judío en la familia de Calisto debido a la relación incestuosa de su abuela.

11. En las Siete Partidas, el rey Alfonso x el Sabio introdujo grandes innovaciones en el Derecho español criminalizando aspectos de la vida real como era el caso de las posibles relaciones amorosas de judíos con cristianos. En la Partida Séptima Título xxiv Ley IX, se advierte del peligro que supone el permitir que jóvenes cristianas puedan convivir con judíos pues rompen el matrimonio sagrado de éstas con la fe católica: «Atrevencia et osadía muy grande facen los judíos que yacen con las cristianas, et por ende mandamos que todos los judíos contra quien fuere probado daquí adelante que tal cosa hayan fecho, que mueran por ello; ca si los cristianos que facen adulterio con las mugeres casadas merecen por ende muerte, mucho más la merecen los judíos que yacen con las cristianas, que son espiritualmente esposas de nuestro señor Jesucristo por razón de la fe et del bautismo que recibieron en nombre dél» (141-42). 
En las Cortes de Toro de 1398, con Enrique III, se decidió imponer el primer tributo a las «mujeres públicas» o «rameras» que vendían sus servicios en las plazas. Se aplicaron leyes que habían sido aprobadas anteriormente para disuadir a las jóvenes como Melibea y evitar que se vieran atraídas por dicha práctica ${ }^{12}$. Se condenó la prostitución pero sin llegar a ilegalizarla ya que siguiendo los principios de San Agustín se entendía que su prohibición originaría la creación de nuevos vicios que atacarían la sagrada institución del matrimonio. Uno de los códigos de leyes de la época que intentó regular la profesión fue el Fuero Real que establecía que cualquier tipo de pecado contra la naturaleza iba a ser castigado con la castración para luego ser ahorcado por los pies y abandonado sin haber recibido sepelio. Por otra parte, Las Siete Partidas ${ }^{13}$ del rey Alfonso x el Sabio (de finales del siglo xiII) condenaba a muerte a los pecadores, menos a los que fueran menores de 14 años o víctimas de violación homosexual. En el caso de adulterio ${ }^{14}$, tanto la mujer adúltera como el amante podían ser condenados a muerte y ejecutados no sólo por su marido sino también por su padre. En cuanto a las cortesanas, no podían ser menores de 12 años, tenían que ser vírgenes o viudas respetables y se les castigaba con 300 azotes en la espalda.

Con la llegada del Cristianismo y la puesta en vigor del segundo Concilio de Letrán, se defendían las ideas de castidad, matrimonio y virginidad, y se les otorgó gran valor religioso limitando la libertad sexual de la sociedad. Se buscaba frenar la lujuria. Se intentaba, además, apartar a las prostitutas de las calles y confinarlas en burdeles en los arrabales de la ciudad para que no fueran ejemplo para las doncellas honradas y así no peligrara su pureza. Estas mismas leyes que intentaron sacarlas de la ciudad tuvieron que ser las razones por las que Celestina se mudó de la casa de al lado de la cuesta del río donde solía vivir al barrio — marginal - en el que ahora se había asentado (Lacarra 46). Era un área más peligrosa que no gozaba de la seguridad de los barrios ricos y donde en cualquier encrucijada se podía encontrar la muerte, como comenta Celestina a Elicia:

No temo esso, que de día me aviso por do venga de noche, que jamás me subo por poyo ni calçada sino por medio de la calle. Porque como dizen, no da passo se-

12. Una de las razones por las que he decidido considerar a Melibea en los mismos términos que el resto de los sujetos femeninos de mi estudio es que ella se ve atraída por la profesión, y no por el conjuro de Celestina como algunos críticos han propuesto. Conocía a Celestina de cuando era vecina suya y mantiene el contacto de Lucrecia que no sólo le informa, sino que la inicia en la aceptación de nuevos roles: amante y prostituta privada del caballero.

13. En Las Siete Partidas, el rey Alfonso x el Sabio reformó las medidas legislativas que ya había adelantado en el Fuero Real.

14. El Libro IV Título viI Ley I, el rey Alfonso x analiza la situación legal de los adulterios: «si mugier casada fiziere adulterio, amos sean en poder del marido e faga dellos lo que quisiere e de quanto que an, así que non pueda matar el uno dellos e dexar el otro» (Fuero Real 432). 
guro quien corre por el muro, y aquel va más sano que anda por llano. Más quiero ensuciar mis çapatos con el lodo que ensagrentar las tocas y los cantos. (XI: 254)

Otra de las medidas que se adoptó fue la de diferenciar a las prostitutas públicas de las mujeres respetables otorgándoles un tipo de vestido que las identificara, ahora que tenían un nombre que establecía una barrera entre ellas. Sin embargo, hay que esperar hasta el Siglo de Oro para adjudicarles vestimentas de color amarillo como símbolo distintivo de su oficio $^{15}$. Este dato va a ser muy importante porque hasta entonces no se va a poder apreciar quién es una mujer pública y quién no. En la comida en casa de Celestina donde se reúnen los criados con sus amadas, Areúsa increpa furiosa a los sirvientes por considerar bella a Melibea ya que son sus riquezas, y no su honra, es decir, su reputación, fama y comportamiento, las que distinguen la una a la otra: "las obras hazen linaje, que al fin todos somos hijos de Adam y Eva. Procure de ser cada uno bueno por sí, y no vaya a buscar en la nobleza de sus passados la virtud» (IX: 229). Así, ella rompe todo sistema de jerarquía social para igualar a la noble doncella con el grupo de mancebas. Se puede decir que para Areúsa, Melibea se viste y se comporta como cualquier prostituta ${ }^{16}$.

Todas estas legislaciones, dejaban completamente desprotegidas a las rameras pero aún contaban con la ayuda de comunidades como la de algunos monasterios, que les ofrecían refugio y les permitían quedarse allí mientras tenían a sus hijos bastardos. Por eso, el hecho de que Elicia y Areúsa intenten protegerse tras la muerte de Celestina es un reflejo de cómo ellas ya no tienen ese escudo protector tras perder los vínculos familiares con Celestina. La muerte de ésta rompe su relación de primas y de compañeras de profesión, y ahora van a convertirse en competidoras del mismo negocio renunciando a vivir juntas. Areúsa comenta a Elicia que "yo ya siento la mejoría más que antes» (XVII: 310) pues ya no tiene tanta

15. Manuel Fernández Álvarez comenta que «la rigidez de las costumbres podría rastrearse en el hecho de obligar a las meretrices a llevar un atuendo especial (mantillas cortas, de color amarillo, sobre las sayas), así como la sujeción de pasar la noche en 'casa de la mancebía', desde que sonaba el toque de oración» (234; énfasis mío).

16. En la versión cinematográfica de Vera, todas las doncellas visten de color crema. En ésta, sólo Lucrecia escoge colores fuertes como el rojo para sus ropas con la intención de mantenerse un poco al margen de la comunidad de rameras a la que todavía no ha accedido. Este aspecto común que distorsiona la estructura social está compensado con el reparto pues se ha hecho una perfecta elección, en mi opinión, de actrices para dar un mensaje determinado: Melibea no era una prostituta como el resto de las doncellas. Todas las actrices seleccionadas para el papel de ramera o de criada (Candela Peña como Elicia, Maribel Verdú como Areúsa, y Nathalie Seseña como Lucrecia) tienen una reputación en España de haber realizados papeles donde se incluían escenas de sexo, mientras que Penélope Cruz (Melibea) últimamente se ha mantenido reacia a mostrar su cuerpo, lo cual distanciaría a la doncella del resto de mujeres públicas, aunque no del todo porque en su actuación manifiesta una gran pasión por Calisto (Juan Diego Botto). 
competencia. También, pierden ellas el parentesco familiar que tenían con sus amantes ya que, aparte de la pérdida de dinero que les produce su condena, se ven faltas de su protección. Por ello, lloran amargamente y visten luto por su ejecución. Areúsa es la que más llora porque depende por completo de lo que le dé su amigo para mantener su situación privilegiada. Elicia, sin embargo, se entristece menos pues ella se va a quedar con la casa y el negocio de Celestina, que tiene una reputación que le puede ayudar a sobrevivir.

Privadas del apoyo social, se tenían que esconder para ejercer su profesión pues la prostitución se había convertido en una actividad clandestina: "Muchas encubiertas vi entrar en su casa; tras ellas hombres descalços, contritos, y reboçados, destacados, que entravan allí a llorar sus peccados» (I: 110-11). Elicia no sale del burdel, Lucrecia aún no ha mantenido ninguna relación, Melibea no quiere reconocer en público o en su casa la atracción hedonista que siente por Calisto para no ver dañada su honra, y Areúsa recibe a sus amantes en su morada para que sus vecinos no sepan a qué se dedica y así poder vivir en un barrio fuera de los arrabales: «Entremos quedo; no nos sientan sus vezinos» (VII: 200). Por ello, Melibea abandona su casa y se va al jardín con su criada donde crean una nueva micro-sociedad que se opondría a la honradez de la casa de Peblerio. Ama y criada forman una unión o un subconjunto dentro del grupo general de prostitutas para conseguir llevar a cabo sus intenciones.

Podemos observar toda una serie de términos que consolidan esa unión de intereses y que crea un árbol genealógico completo en el que se incluirán todas las prostitutas de la obra. En La Celestina, las mancebas formaban junto con los mozos que las solían visitar una especie de familia en la que había una relación simbiótica de beneficio. Los enamorados obtenían el amor de las hermosas doncellas a cambio de su mantenimiento y protección como alianza entre los amantes - asegurándose que nadie las molestara. La alcahueta es considerada la «madre» (I: 105) de todas las prostitutas que tiene bajo su protección; los sirvientes que son asiduos visitantes de su burdel se hacen llamar «hijos»" ${ }^{17}$ (XII: 268) suyos — incluso antes de cometer el «matricidio» - pues ella les proviene todo el placer que ellos quieren consiguiéndoles buenas mozas; $y$ entre las prostitutas y los criados se llaman "primas» ${ }^{18}$ (IV: 151) o "primos» (I: 104) siendo Celestina la «tía» (IV: 152) de todos ellos por ser el vínculo que relaciona a todos entre sí. Además, la «puta vieja» (I: 108) debe parte de su saber a la abuela

17. El pensar que los criados son hijos de Celestina, es decir, unos «hijos de puta,» podría parecer una temeridad pero el caso de Pármeno es muy claro pues su madre se había dedicado a la prostitución. En cuanto a Sempronio, poco se sabe de su pasado. Sin embargo, no era extraño que los hijos de estas mujeres pecadoras entrarán a servir en las casas de familias respetables pertenecientes a la nobleza.

18. Deyermond comenta que en la Edad Media las prostitutas se solían tratar como primas (13). 
de Elicia, a la que aventajó tras estar un año bajo su protección (VII: 210), y a la madre de Pármeno, que le enseñó todo lo que sabe (III: 142).

En el siguiente gráfico, se puede ver la transmisión de conocimientos que se producía en cada generación, la cual representaba un gran peligro para las autoridades civiles - por potenciar la existencia de barrios bajos o marginales - y religiosas - por robar almas cristianas.

\section{Gráfico de prostitución en la familia de prostitutas en La Celestina}

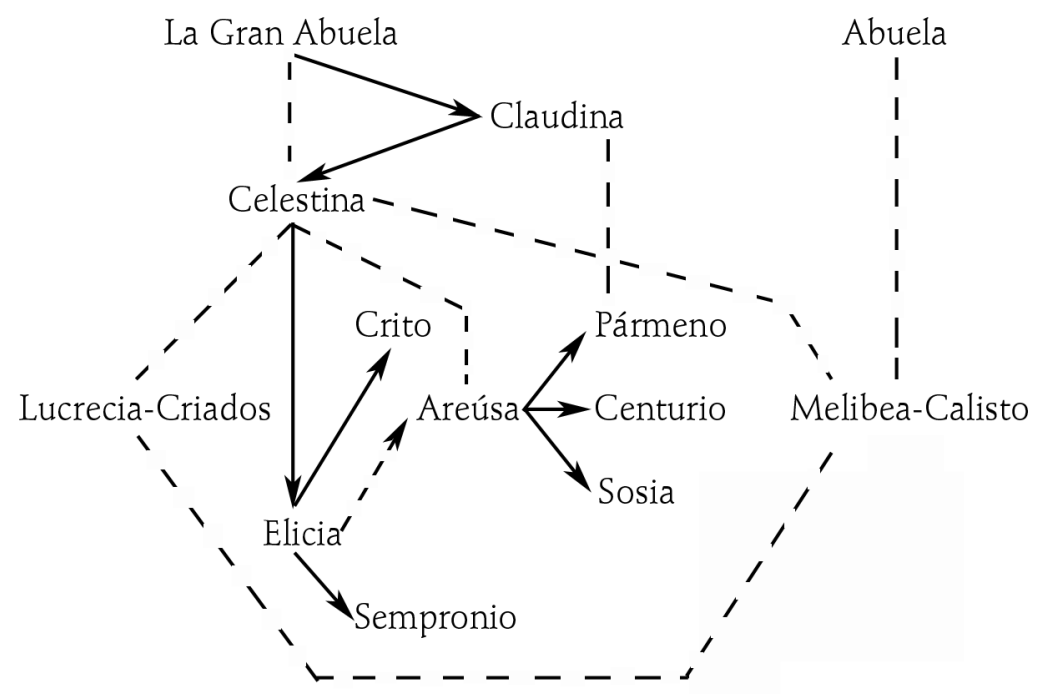

Sin embargo, lo realmente importante de este grupo familiar ${ }^{19}$ es que en él, también, tienen cabida miembros de la nobleza. Calisto, cuya abuela ya había iniciado la línea de transmisión por ser infiel a su marido, llamará «tía» (I: 108) a Celestina pues ella es la que le consigue el amor de la doncella que él pretendía, mientras que Melibea la llama «madre» (Iv: 155) por ser la que intercede por ella para lograr satisfacer su pasión por el joven noble. Esto representa una trasgresión de fronteras sociales, la atracción de las capas altas de la sociedad por medio de las clases marginales,

19. Las relaciones que se establecen dentro de este diseño innovador de parentesco familiar que propongo son de dos tipos. Por una parte, puede haber una influencia directa, representada por una línea continua, de cada prostituta con su amante o del miembro de la generación anterior sobre su pupilo como es el caso de Celestina con Elicia, y de la "Gran Abuela» con Claudina, cuyo arte inculcó después a Celestina. Por otra parte, también se puede hablar de una dependencia parcial entre dos miembros de la misma familia, representada por una línea discontinua, como es el caso de las prostitutas que no se protegen en la casa de Celestina pues tienen iniciativa propia, y de algún criado que recibe una influencia adicional de algún miembro de la generación anterior. 
lo cual es un ejemplo claro de la situación de crisis en la que estaban los valores ético-sociales de la España de finales del siglo xv. Por otra parte, son de destacar los términos afectivos entre las prostitutas - Celestina y Claudina derivados de Celeste y Claudia - que representan la simpatía que había entre ellas por las condiciones de vida en las que vivían y por la vulnerabilidad del estado en el que se encontraban.

En esa estructura familiar que defiendo, se podría hablar de cinco categorías de individuos representadas por los nombres de cada uno de los sujetos femeninos de la obra. Barbera comenta que el Arcipreste de Hita, en su Libro de buen amor, habla de una Trotaconventos y una Doña Endrina cuando, en realidad, está presentando al personaje que corresponde a una categoría, de alcahueta y de ama, en este caso (794). Entonces, al igual que Barbera ha analizado a estos modelos como arquetipos, se puede ver que Rojas está tratando a cada una de las mujeres de su tragicomedia como ejemplos de un tipo determinado de ramera.

Celestina es una prostituta venida a menos, una "puta vieja» (I: 109). Siendo ella joven, tuvo una gran fama antes de ser capaz de poder regentar un burdel en la mejor zona de la ciudad, y tenía allí a nueve mozas a su cargo. Los caballeros la favorecían con su protección debido al buen servicio que les hacía. En cambio, ahora se conforma con regentar una casa pública en los arrabales donde se ve expuesta a cualquier peligro. Sin embargo, su decadencia es tanto económica como física. Melibea no reconoce a la alcahueta al principio porque la recordaba más bella ${ }^{20}$ : «Figúraseme que eras hermosa; otra pareces; muy mudada estás» (Iv: 157). La misma Celestina lo confiesa pues, a pesar de que ahora ya es una mujer mayor de "sesenta años» (XII: 273), «encanecí temprano, y paresco de doblada edad» (IV: 158). Las mujeres públicas sufrían de enfermedades venéreas y este envejecimiento prematuro podría ser consecuencia de la mala vida que llevaban pues por estar «lujuriando [su cuerpo] padesçe en todos sus naturales cinco sentidos» (Martínez 73). Rojas adelanta ya su crítica al amor mundano y al desbordamiento de la pasión, luego recuperada en el acto XXI en el discurso de Pleberio, por hacer perder la vida y la razón de las personas.

En su casa con Elicia, Celestina utiliza a los criados para ganarse la vida, al igual que lo hacía cuando era joven. No hay pruebas textuales para asegurar exactamente cómo Celestina practicó la prostitución, sea regentando un prostíbulo de forma clandestina sea siendo obligada a prostituirse, pero sí que las hay para saber que lo hizo mientras estaba casada aprovechándose de la protección que le ofrecía el matrimonio (Brackett 273-74).

20. Las prostitutas eran guapas y los criados hacen referencia a la belleza de sus amadas: «aquélla es Elicia, criada de Celestina y amiga de Sempronio, una muy bonita moça [y] allí mora una hermosa mujer muy graciosa y fresca, enamorada, medio ramera, pero no se tiene por poco dichoso quien la alcança a tener por amiga sin grande escote, y llámase Areúsa» (xIv: 293). 
Celestina había engañado a su marido como se desprende de la conversación entre Pármeno y Calisto: « $\bigcirc$ qué comedor de huevos assados era su marido!» (I: 109). En aquella época, además de que en la tradición judía se solía comer huevos en los funerales, también se pensaba que un marido cornudo no quebraría los huevos cuando los asara.

Si antes había mentido a su esposo, cuando él muere juega con los criados de Calisto a los que hace creer que son los dueños de los corazones de sus amadas. A la llegada de Sempronio al burdel, Celestina avisa a Elicia de que tiene que esconder a Crito porque otro de sus amantes ha llegado (I: 104). Así, puede mantener vivo el negocio, lo cual es muy importante para ella porque se rige por la avaricia. Se preocupa por el dinero y así a su llegada a casa de Calisto con Sempronio manda al criado que le diga a su señor "que cierre la boca y comence abrir la bolsa» (I: 116). De este negocio, va a conseguir cien monedas de oro y una cadena de oro. Pero, esta cupiditas $^{21}$ acaba siendo su condena porque la asesinan por no querer compartir sus ganancias con sus cómplices y mozos que ella había acercado al mundo de la prostitución. Sin duda, ésta es una de las características más importantes de la alcahueta. Debido a su negocio, necesita que haya mujeres que se dediquen a su profesión para conseguir dividendos. Elicia, Areúsa, Lucrecia y Melibea le ayudan a ganar dinero a la vieja de una forma o de otra por lo que se podría decir que casi en su totalidad ellas trabajan para la alcahueta.

Una de ellas, Elicia, es el caso más claro de prostitución en la obra por lo que su análisis no representa un gran desafío. Representa la categoría de "prostituta pública». Su papel es el de trabajar en la casa que regenta Celestina y ganarse los favores de los criados. La primera escena en la que aparece nos muestra mucho de su personalidad hedonista. Cambia de amante sin problemas con el fin de mantener a los dos contentos aunque para ello se tenga que servir del engaño. A la llegada de Sempronio, le cuenta a Crito que ha llegado su primo y que se tiene que ir por su bien. Luego, cuando Sempronio vuelve a la casa, Elicia mantiene una conversación con Celestina, a la que le cuenta que ha tenido dos visitas más durante su ausencia, dato que nos confirma lo solicitada que estaba la moza. No depende de nadie más que de ella misma y de Celestina pues le provee de un techo para ejercer su profesión, y le enseña su arte para cuando ella falte en el futuro (VII: 210). Por ello, cuando muere Sempronio, a pesar de guardar luto, no sufre tanto como Areúsa y prefiere quedarse en casa de Celestina porque seguro que allí encontrará a otro criado que la quiera. Elicia es un ejemplo de aquellas doncellas que perdieron su honra por entregarse al placer de la carne, y de cuyo mundo ya no puede salirse.

21. Se le llama cupiditas a la avaricia, la codicia o el deseo de Celestina. En el Corbacho, se repudiaba la codicia de las mujeres pues «doblegará una muger que non es fuerte como piedra» (Martínez 148). 
Areúsa ${ }^{22}$, en cambio, se ajusta más al modelo de "cortesana», es decir, que depende económicamente de un solo hombre: «me da todo lo que he menester; tiéneme honrrada; favoréceme y trátame como si fuesse su señora» (VII: 204). Esta consideración es un tanto problemática porque su "amigo" es un soldado de rango menor por lo que no recibiría mucho dinero de él, y las cortesanas solían depender de caballeros de la corte. Sin embargo, al considerarla de esta manera sí que se demuestra un mayor control de las pasiones o por lo menos una menor lascivia de la mujer. De hecho, no quiere engañar a su amante (VII: 203) a pesar de que esté lejos de ella como si hubiera una relación amorosa más profunda entre ellos que la mera atracción sexual. Tanto quiere a sus pretendientes que es ella la que luego propone a Elicia vengarse de Melibea y Calisto pues ellos acabaron con las vidas de los criados, los que les quitaron el amor que tenían.

Al principio Areúsa no está bajo el control de Celestina, y vive en un buen barrio pero la alcahueta la irá acercando a la comunidad de prostitutas convenciéndola de unirse a la familia que ella dirige. Ella mantiene una distancia pues le recuerda a Celestina que «no soy tan viciosa como piensas» (VII: 202), pero luego acaba acostándose con Pármeno y Centurio, además de prometerle amores a Sosia cuando su amado muere, por lo que deja de ser una cortesana y se convierte en una prostituta pública, aunque monógama como dice Celestina: "¿de una sola gotera te mantienes?» (VII: 205). Celestina la ha ido atrayendo poco a poco al grupo prometiéndole verdadero placer: "góze él de ti y tú dél, que aunque él gane mucho, tú no pierdes nada» (VII: 205). Pierde su estatus privilegiado durante un tiempo por tener que servir a dos hombres a la vez ya que se consideraba mujer pública a aquella que se hubiera acostado con dos caballeros. Los mismos criados ya no la distinguen de los otros miembros de su gremio y creen que "esta mujer es marcada ramera según tú me dixiste» (XIX: 319). Luego, volverá a distanciarse en sus futuras relaciones con Sosia recuperando su condición de amante fiel y desapareciendo de la acción.

Aún más al margen de los hechos se mantiene Lucrecia, que sólo aparecerá en momentos cruciales como testigo o cómplice. Su identificación con la familia de prostitutas es provisional pues todavía no ha adquirido todas las condiciones que la conviertan en una de ellas. Por ello, he optado por considerar que es una "prostituta joven» que está aprendiendo el arte gracias a los consejos de la vieja alcahueta, y del comportamiento de su ama, a la que ve estar atraída por la prostitución y a la que observa en sus encuentros amorosos con Calisto en el jardín. Sin duda, Lucrecia

22. La crítica no ha prestado mucha atención a la naturaleza individual de Areúsa y la ha equiparado con Elicia cuando cada una de ellas representa un modelo diferente de mujer pública. 
es la más honrada de todas porque, desde el principio, mantiene una distancia y previene a su dama del peligro que representa Celestina. No obstante, no es que esté en contra de la vieja por ser lo que es, sino que no quiere perder el privilegio de vivir en una casa honrada. Durante el siglo XV, hubo una gran emigración del campo a la ciudad y muchas mujeres pobres se refugiaban en las casas de las señoras trabajando como criadas para no caer en las redes de la prostitución y la pobreza. En la reunión con Celestina, Areúsa explica que estas criadas no tienen mucha libertad ya que "ni gozan deleyte ni conocen los dulces premios de amor» (IX: 232) por estar muy controladas por el ama. Sin embargo, esta censura desaparece cuando Lucrecia se encuentra en presencia de otras prostitutas. Su entrada en la casa de Celestina, donde ve a "tanta gente y tan honrrada» (Ix: 234), la introduce en el mundo de la prostitución y sirve como crítica social, pues enfrente de ella tiene a mujeres y hombres cuyo comportamiento es idéntico al de los amos, pero cuya reputación no goza de tan buena fama. Ya es casi una de ellas pero todavía le queda bastante para completar la transformación iniciada en su encuentro con Celestina, donde le promete que le ayudará a mejorar su aspecto físico para poder atraer a los hombres: "yrás a casa y darte he una lexía con que pares essos cabellos más que el oro; no lo digas a tu señora. Y aun darte he unos polvos para quitarte esse olor de la boca que te huele un poco» (IV: 169). La criada le contesta que «más necessidad tenía de todo esso que de comer» (Iv: 169), mostrando las ansias de la moza por tomar su bautismo en la profesión. Según Marjorie Ratcliffe, las criadas que venían del campo preferían ser prostitutas al principio para luego convertirse en cortesanas cuando subieran a mejor nivel (348). No obstante, esta última transformación no tiene lugar en la obra. Lo único que conocemos es que Lucrecia va a aprovechar estas nuevas artes para enamorar a los criados de la casa que ella pretende.

Es una atracción al mundo de la prostitución parecida a la que experimenta su ama. El considerar a Melibea como una prostituta, en este caso privada por recibir a su amado en casa, presenta muchos problemas, lo cual ha llevado a muchos críticos, como Foster, Valbuena y Correa, a desechar esta opción y a inclinarse por la interpretación del conjuro de amor que la vieja alcahueta realiza para conseguir que la joven dama acepte al noble caballero (III: 147). Sin embargo, Elizabeth Sánchez considera que el conjuro no es el único elemento que contribuye a la caída de la dama y a su entrega a la pasión, sino que también es producto de la atracción de los dos jóvenes.

En mi opinión, Melibea ya lleva la pasión adentro mucho antes de que se produzca el intercambio de objetos mágicos. Ya en la primera escena, en el encuentro de los amantes en el jardín de la dama, a pesar de que la doncella rechaza el acercamiento amoroso del caballero, le promete buena fortuna si no se deja vencer en su intento: «Pues, jaún más igual galar- 
dón te daré yo, si perseveras!» (I: 87). Su rechazo es sólo una máscara que tiene que llevar para no poner en peligro ni su honra ni la de sus ancianos padres. Por ello, utiliza los servicios de la alcahueta y de su criada. Su confianza en Celestina, a la que llama «madre» (Iv: 156), la convierte en otra de sus discípulas, y su confesión con Lucrecia representa un pacto de ayuda mutua para que ella pueda disfrutar del amor de Calisto. Celestina y Lucrecia la van a introducir en el mundo del placer sexual que ella parece desconocer o al que teme acceder. A pesar de ser una doncella virgen, no parece que desconozca el arte del amar cuando le dice a su amado que le va a enseñar cómo satisfacer su pasión: "Holguemos y burlemos de otros mil modos que yo te mostraré; no me destroces ni maltrates como sueles» (XIX: 323-24). Este comentario está muy en consonancia con el tipo de personaje que es la doncella pues sus comentarios y comportamiento confunden al lector no sabiendo si es tan inocente como pueda parecer o si, en verdad, como intento demostrar, se resguarda bajo el escudo protector de sus padres fingiendo ser una buena hija.

Su iniciación consiste en un decir sin decir donde ella no se atreve a pronunciar el nombre del amado para fingir no saber nada mientras insiste constantemente en que Celestina le cuente quién es el enfermo que ella puede sanar: "pide lo que querrás, sea para quien fuere» (IV: 159). Ella sabe perfectamente quién es el desdichado por lo que su reacción de ira no es más que una farsa que oculta sus verdaderos sentimientos. Recuperando la tradición platónica del amor como medicina, Melibea quiere ayudar a sanar al mozo doliente: «Por Dios, [que] sin más dilatar me digas quién es esse doliente, que de mal tan perplejo se siente que su pasión y remedio salen de una misma fuente» (IV: 161; énfasis mío). Sin embargo, este amor es más carnal que espiritual y es un dolor que luego va a sufrir ella cuando vea las barreras que los separan. Pero, ella está decidida y con la entrega del cordón que ciñe su cintura (Iv: 168), símbolo de su castidad, invita a Calisto a que mantenga sus esperanzas, y renuncia a su voto religioso pues entrega el objeto sagrado, bendecido en reliquias, que santificaba su cuerpo de mujer. También esta prenda sirve de intercambio comercial entre caballero y dama. Se distingue del pago de joyas o monedas por los servicios de una mujer pública pero eso es, más bien, debido a que Melibea es de familia rica y de más alto linaje que la de Calisto. Además, no hay pruebas textuales de que el resto de las rameras, menos Celestina, reciban algo de sus amados y no por ello han dejado de ser consideradas como tales.

Melibea ya se ha decidido a entregarse a la pasión y, de paso, unirse al grupo de mujeres, ya que ahora es ella la que decide sobre su vida oponiéndose a los planes de boda de sus padres ${ }^{23}$, preocupados por la honra

23. Habiendo oído ruidos extraños durante el mes en que Melibea ha sido visitada por su amado Calisto, los padres sospechan que su hija ha desobedecido el consejo de la madre de 
de su hija: «ni quiero marido, ni quiero padre, ni parientes» (xvi: 305). Se vuelve tan mentirosa como su maestra para ocultar su falta. Así, a la vuelta de su encuentro con Calisto, responde a su padre que era la criada la que hacía ruido pues "salió por un jarro de agua para mí, que avía [gran] sed» (XII: 266). Estaba sedienta de pasión y no se ve nunca satisfecha con el amor de Calisto como si no tuviera suficiente ${ }^{24}$. Por ello, la pérdida del amado es para ella algo terrible porque, por una parte, pierde la medicina que le estaba curando su dolencia: « $\mathrm{O}$ la más de las tristes, triste, $\tan$ poco tiempo poseýdo el plazer, tan presto venido el dolor!» (XIX: 328). Y, por otra parte, se ve desprovista de la fuente de pasión que acababa de empezar a disfrutar: " $O$ ingratos mortales, jamás conoces vuestros bienes sino quando dellos carescéys» (XIx: 328). Tales sucesos le condenan a la muerte. No le interesa seguir viviendo si no tiene el amor de Calisto, hecho que la separa del resto de sus parientes en el prostíbulo.

En resumen, a finales del siglo xV, en la sociedad medieval en España, se estaba produciendo una transformación de principios ético-morales que intentaba regular la vida de los creyentes y controlar su tendencia lujuriosa imponiendo nuevos valores religiosos. El clero produjo obras reglamentarias, como el Libro de buen amor o el Corbacho, que proponían un cambio de actitud en los jóvenes mozos y atacaban las malas artes de las mujeres que hacían que perdiesen la razón. La Celestina, también, pertenece a esta tradición misógina «mostrándoles los engaños que están encerrados en sirvientes y alcahuetas» (67), pero además rompe con las barreras sociales de la época no sólo castigando la sexualidad de las mujeres públicas, sino también de las que se comporten como ellas. El amor es la fuerza que lleva a todo el mundo a la perdición si no se trata de un sentimiento puro, si conlleva el abandono de toda moralidad por entregarse al placer carnal. La alcahueta, las dos rameras y las dos mozas atraídas al mundo del pecado son cinco ejemplos de esta crisis de moralidad en la sociedad medieval española, de esta lujuria que predecía la perdición de toda esperanza. Sólo con la muerte o el aislamiento de estas mujeres desaparecía la amenaza del pecado, y se finalizaba la obra con un mensaje de un autor preocupado por la lujuria de sus ciudadanos.

no recibir a Celestina, y perdido su honor, víctima de su pasión carnal. Aún así, van a intentar mantener el nombre de la familia limpio arreglándole un matrimonio que restituya su pecado: «no ay cosa con que mejor se conserve la limpia fama en las vírgenes que con temprano casamiento» (XVI: 302).

24. La imagen del agua y de la sed como metáfora de la pasión tiene raigambre clásica. Además, hay un paralelo entre la salida de la doncella al jardín para satisfacer su pasión con el tema de la venatio amoris del inicio de la tragicomedia, donde Calisto persiguiendo un halcón suyo se adentra en el jardín de Melibea, a la que empieza a cortejar. 


\section{Obras citadas}

ALFONSO X EL SABIO. Las Siete Partidas. Antología. Madrid: Confederación Española de Gremios y Asociaciones de Libreros, 1984.

- Leyes de Alfonso X: Fuero Real. Ed. Gonzalo Martínez Díez. Ávila: Fundación Sánchez Albornoz, 1988.

BARBERA, Raymond E. "A Harlot, A Heroine». Hispania 48. 4 (Diciembre 1965): 790-99.

BRACKETT, John K. "The Florentine Honesta and the Control of Prostitution, 1403-1680». Sixteenth Century Journal 24. 2 (Verano, 1993): 273-300.

CORREA, Gustavo. "Naturaleza, religión y honra en La Celestina». PMLA 77. 1 (Marzo, 1962): 8-17.

DEYERMOND, Alan. "Female Societies in Celestina». Fernando de Rojas and Celestina: Approaching the Fifth Centenary. "Proceedings of an International Conference in Commemoration of the $450^{\text {th }}$ Anniversary of the Death of Fernando de Rojas, Purdue University, 21-24 November 1991». Eds. Ivy A. Corfis and Joseph T. Snow. Madison WI: The Hispanic Seminary of Medieval Studies, 1993. 1-31.

FERNÁNDEZ ÁLVAREZ, Manuel. Casadas, Monjas, Rameras y Brujas. La olvidada historia de la mujer española en el Renacimiento. Madrid: EspasaCalpe, 2002.

FOSTER, David William. "Some Attitudes towards Love in the 'Celestina'». Hispania, 48. 3 (Septiembre, 1965): 484-92.

LACARRA, María Eugenia. "La evolución de la prostitución en la Castilla del siglo XV y la mancebía de Salamanca en tiempos de Fernando de Rojas». Fernando de Rojas and Celestina: Approaching the Fifth Centena$r y$. "Proceedings of an International Conference in Commemoration of the $450^{\text {th }}$ Anniversary of the Death of Fernando de Rojas, Purdue University, 21-24 November 1991». Eds. Ivy A. Corfis and Joseph T. Snow. Madison WI: The Hispanic Seminary of Medieval Studies, 1993. 35-78.

MARTÍNEZ DE TOLEDO, Alfonso. Arcipreste de Talavera o Corbacho. Ed. Michael Gerli. Madrid: Cátedra, 1998.

RATCLIFFE, Marjorie. "Adulteresses, Mistresses and Prostitutes: Extramarital Relationships in Medieval Castile». Hispania 67. 3 (Septiembre, 1984): 346-50.

RIPA, Cesare. Baroque and Rococo Pictorical Imagery. The 1758-60 Hertel Edition of Ripa's Iconologia with 200 Engraved Illustrations. Nueva York: Dover, 1971.

ROJAS, Fernando de. La Celestina. Ed. Dorothy S. Severin. Madrid: Cátedra, 1992.

ROJAS, Fernando de. La Celestina. Ed. Francisco J. Lobera, et al. Barcelona: Crítica, 2000. 
RUIZ, Juan. Libro de buen amor. Ed. Alberto Blecua. Madrid: Cátedra, 1998.

SÁNCHEZ, Elizabeth. "Magic in La Celestina». Hispanic Review, 46. 4 (Otoño, 1978): 481-94.

VALBUENA, Olga Lucía. «Sorceresses, Love Magic, and the Inquisition of Linguistic Sorcery in Celestina». PMLA 109. 2 (Marzo, 1994): 207-24.

VERA, Gerardo, director y guionista. La Celestina. Videocasete.Actuando Terele Pávez (Celestina), Penélope Cruz (Melibea), Candela Peña (Elicia), Maribel Verdú (Areusa) y Nathalie Seseña (Lucrecia). Lola Films, 1995.

WISE, David O. «Reflections of Andreas Capellanus's De Reprobatio Amoris in Juan Ruiz, Alfonso Matinez, and Fernando de Rojas». Hispania 63. 3 (Septiembre, 1980): 506-13.

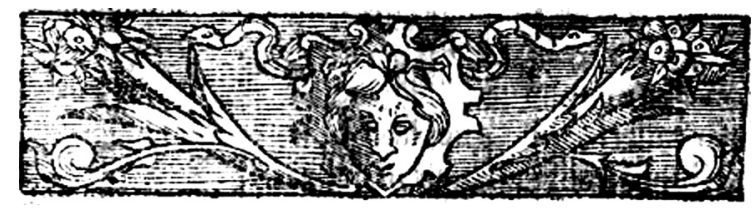


ABRIL-SÁnCHEZ, Jorge, "Una familia de meretrices: prostitutas públicas y privadas, cortesanas, rameras y putas viejas en $\mathrm{La}$ Celestina», Celestinesca 27 (2003), pp. 7-24

\section{RESUMEN}

LA FIRMA DEL decreto regio de conversión o expulsión de los moriscos de 31 de marzo de 1492 produjo grandes cambios en la sociedad española. Con la publicación de nuevos códigos legislativos, las autoridades civiles pretendían borrar el bagaje cultural heredado de la época pasada y controlar la libertad sexual de una comunidad que se había visto atraída por actividades, como la prostibularia, que atentaban contra los valores ético-religiosos. En La Celestina, Melibea se introduce en el mundo de la prostitución de mano de una alcahueta y sus discípulas, con las que acaba formando una verdadera familia de meretrices.

PALABRAS ClAVE: La Celestina, prostitución, sexualidad, familia, hedonismo, genealogía.

\section{ABSTRACT}

THE SIGNING OF the royal decree of conversion or expulsion of the Moorish on March 31st, 1492 entailed huge changes in the Spanish society. With the publication of new law codes, the civil authorities tried to erase any cultural heritage from the former historic period and to control the sexual freedom of a community that had felt attracted to activities, as that of the brothel, which threatened the moral values. In La Celestina, Melibea is introduced to the world of prostitution by a bawd and her disciples, with whom she ends up building a whole family of prostitutes.

KEY WORDS: La Celestina, prostitution, sexuality, family, hedonism, genealogy.

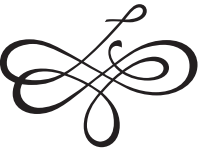

